\title{
Resveratrol decreases cell apoptosis through inhibiting DNA damage in bronchial epithelial cells
}

\author{
YUN ZHANG $^{1,2^{*}}$, LINLIN GUO ${ }^{3,4^{*}}$, BETTY YUEN-KWAN LAW $^{1}$, XIAOBO LIANG ${ }^{2}$, \\ NING MA ${ }^{2}$, GUOFENG XU ${ }^{2}$, XIAOYUN WANG ${ }^{2}$, XIEFANG YUAN ${ }^{2}$, HONGMEI TANG ${ }^{2}$, \\ QI CHEN $^{1}$, VINCENT KAM-WAI WONG ${ }^{1}$ and XING WANG ${ }^{2}$
}

\begin{abstract}
${ }^{1}$ State Key Laboratory of Quality Research in Chinese Medicine, Macau University of Science and Technology, Taipa, Macau 999078; ${ }^{2}$ Laboratory of Inflammation and Allergy, The Affiliated Hospital of Southwest Medical University, Luzhou, Sichuan 646000, P.R. China; ${ }^{3}$ Department of Obstetrics and Gynecology, The Ohio State University Wexner Medical Center; ${ }^{4}$ The James Cancer Hospital and The Comprehensive Cancer Center, The Ohio State University, Columbus, OH 43210, USA
\end{abstract}

Received August 14, 2019; Accepted January 28, 2020

DOI: $10.3892 /$ ijmm.2020.4539

\begin{abstract}
One of the major risk factors for asthma development is exposure to environmental allergens. House dust mites (HDM) can induce DNA damage, resulting in asthma. Resveratrol (RES) produced by several plants, has anti-apoptotic properties and may affect a variety of biological processes. The aim of the present study was to investigate the protective role of RES against apoptosis in bronchial epithelial cells. C57BL/6J mice treated with HDM exhibited high levels of cell apoptosis, while RES significantly reversed this process. Induced DNA damage was more severe in the HDM group vs. the HDM combined with RES group. This result was confirmed by immunostaining and western blot analysis of the protein expression of the DNA damage-related gene $\gamma \mathrm{H} 2 \mathrm{AX}$, which was highly induced by HDM. In addition, treatment with RES protected bronchial epithelial cells exposed to HDM from DNA damage. RES decreases reactive oxygen species levels to inhibit oxidative DNA damage in bronchial epithelial cells. Furthermore, compared with the HDM group, induced cell apoptosis could be attenuated by RES in the group of combined treatment with RES and HDM. A DNA repair inhibitor augmented DNA damage and apoptosis in bronchial epithelial cells,
\end{abstract}

Correspondence to: Dr Xing Wang, Laboratory of Inflammation and Allergy, The Affiliated Hospital of Southwest Medical University, 25 Taiping Street, Luzhou, Sichuan 646000, P.R. China E-mail: wx_eliot_881014@163.com

Dr Vincent Kam-Wai Wong, State Key Laboratory of Quality Research in Chinese Medicine, Macau University of Science and Technology, Room 704a-02, Block H, Taipa, Macau 999078, P.R. China

E-mail: bowaiwong@gmail.com

${ }^{*}$ Contributed equally

Key words: resveratrol, house dust mites, cell apoptosis, DNA damage, bronchial epithelial cell, asthma whereas RES significantly attenuated cell apoptosis through inhibiting DNA damage.

\section{Introduction}

Asthma is a chronic condition that causes intermittent inflammation and narrowing of the airways in the lungs. One of the major risk factor of asthma development is exposure to environmental allergens (1). In addition, house dust mites (HDM) can induce DNA damage and cause asthma (2). Oxidative stress can also cause DNA damage, playing a pivotal role in the development of human immunological diseases $(3,4)$. Asthma is a chronic inflammatory airway disease and oxidative stress may also be involved in its pathogenesis (5). To date, several reports demonstrated that repair of DNA damage is controlled by epigenetics and plays an important role in the process of asthma $(6,7)$. It was previously demonstrated that DNA damage and apoptosis of airway epithelial cells may be caused by cigarette smoke extract $(8,9)$.

Resveratrol (RES; trans-3,5,4'-trihydroxystilbene) is produced by several plants and may be found in red grape skins, red wine and peanuts (10). It was previously reported that cardiovascular protection, anti-inflammatory and anti-aging activities may be regulated by antioxidant status, and anti-apoptotic activity may affect several biological processes (11-15). Additionally, RES can regulate lipid metabolism and affect cytokine expression in the immune system (16-18). Studies indicated that a diet supplemented with RES could improve health and survival in mice with metabolic syndrome $(19,20)$. Previous epidemiological studies demonstrated that elderly individuals on a Mediterranean diet, which is rich in RES, display a markedly reduced risk of cardiovascular disease $(11,12,21)$. Chen et al (22) reported that RES can inhibit DNA damage in cultured human mammary epithelial cells. Previous evidence indicated that RES exerted anti-inflammatory and anti-asthmatic effects on a mouse model of allergic asthma (23-26). Rhee and Lee demonstrated that RES exerts inhibitory effects on airway remodeling through the transforming growth factor- $\beta$ /mothers against decapentaplegic homolog signaling pathway in chronic 
asthma models (27). However, the underlying mechanism and the protective role of RES against cell apoptosis in bronchial epithelial cells remain elusive.

The aim of the present study was to investigate the possible mechanism underlying HDM-induced airway epithelial injury and the protective role of RES against cell apoptosis in the bronchial epithelial cells, in order to determine whether RES can prevent HDM-induced DNA damage and cell apoptosis and whether it represents a novel approach to asthma treatment.

\section{Materials and methods}

Asthma mouse model. A total of $24 \mathrm{C} 57 \mathrm{BL} / 6 \mathrm{~J}$ female mice (Beijing Hfk Bioscience Co., Ltd.), aged 6-8 weeks and weighing 22-26 g, were used in this study. All mice were maintained in a specific pathogen-free facility in the Animal Experimental Center of Southwest Medical University. All animals had ad libitum access to food and water and were maintained in a stable environment at $25 \pm 1^{\circ} \mathrm{C}, 60 \pm 5 \%$ humidity and a 12-h light/dark cycle. The mice were intraperitoneally sensitized on days 1 and 8 with $20 \mu \mathrm{g}$ HDM (cat. no. 326779, Greer Laboratories, Inc.) and $1 \mathrm{mg}$ aluminum hydroxide. One week after the final injection, the mice were treated with HDM intranasal (i.n.), alone or combined with RES (100 mg/kg, intragastric; cat. no. R5010, Sigma-Aldrich; Merck KGaA) daily for 7 days. After 7 days of treatment, the mice were sacrificed by intraperitoneal injection of sodium pentobarbital (100 mg/kg of body weight). The mice were confirmed dead by no spontaneous breathing for 2-3 min and no blink reflex. The lung tissues and bronchoalveolar lavage fluid (BALF) were collected for further study. All animal experiments (including euthanasia) were in compliance with the regulations and guidelines of the Southwest Medical University Institutional Animal Care Committee (Approval no. 20160041) and were conducted according to the AAALAC and IACUC guidelines.

Measurement of airway hyperresponsiveness. A total of $24 \mathrm{~h}$ after the final challenge, whole body plethysmography (Buxco Europe Ltd.) was used to assess total respiratory system resistance after administration of increasing doses of methacholine $(0,6.25,12.5,25$ and $50 \mathrm{mg} / \mathrm{ml})$. Data are reported as peak Penh values.

Histological analysis. Lung tissues were fixed in $10 \%$ neutral-buffered formalin for $24 \mathrm{~h}$ at room temperature and then embedded in paraffin. The tissues were then cut in $5-\mu \mathrm{m}$ sections and subjected to standard hematoxylin-eosin staining (28).

TUNEL assay. Lung tissues were harvested and fixed with $10 \%$ formalin for $24 \mathrm{~h}$ at room temperature, and then embedded in paraffin and cut into 5- $\mu \mathrm{m}$ sections. The tissue sections were deparaffinized and rehydrated, and then treated with citric acid for antigen retrieval for $10 \mathrm{~min}$ at room temperature. The TUNEL Assay Apoptosis Detection kit (cat. no. C1088; Beyotime Institute of Biotechnology) was used to detect DNA fragmentation. In brief, the tissue sections were treated with formaldehyde on ice for $15 \mathrm{~min}$. Subsequently, the tissue sections were washed with phosphate-buffered saline (PBS) and $70 \%$ ice-cold ethanol was added followed by incubation for $30 \mathrm{~min}$. The tissue sections were again washed with PBS three times for 5 min each time, staining solution was added and the sections were incubated at $37^{\circ} \mathrm{C}$ for $60 \mathrm{~min}$. The tissue sections were then washed and treated with ribonuclease A (RNase A) for $30 \mathrm{~min}$ at room temperature, then visualized under a fluorescence microscope (SP5 Leica confocal microscope; Leica Microsystems $\mathrm{GmbH}$ ). The number of TUNEL-positive cells were counted in five different fields for each stained section.

Cell culture and treatment. The bronchial epithelial cells (16HBE) were obtained from Cell Bank of the Chinese Academy of Sciences, and were cultured in DMEM (cat. no. SH30022.01; GE Healthcare Life Sciences) supplemented with $10 \%$ fetal bovine serum (cat. no. 35-076-CV; Corning Inc.) in a humidified atmosphere containing $5 \% \mathrm{CO}_{2}$ at $37^{\circ} \mathrm{C}$. Cells were seeded at 0.5 million cells per well in 6-well plates. At $24 \mathrm{~h}$ after seeding, cells were treated with $10 \mu \mathrm{M}$ RES, $10 \mathrm{mM}$ N-acetyl-L-cysteine (NAC; cat. no. A9165, Sigma-Aldrich; Merck KGaA), or $2.5 \mu \mathrm{M}$ NU7441 (cat. no. S2638; Selleck Chemicals) and then (2 h later) with HDM $(200 \mu \mathrm{g} / \mathrm{ml})$ and incubated for an additional $12 \mathrm{~h}$. Control cells were incubated with an equal amount of DMSO.

Single-cell gel electrophoresis assay. A single-cell gel electrophoresis assay or Comet assay was used to detect DNA damage. Bronchial epithelial cells $\left(3 \times 10^{5}\right.$ cells) were cultured in 6-well plates and exposed to different treatment conditions. Cells were cultured with HDM, with or without the presence of RES or NAC and DMSO was used for the control group. After $12 \mathrm{~h}$ of treatment, the Comet assay was performed using CometChip Reagent kit (Trevigen, Inc.) according to the manufacturer's protocol.

Paraffin-embedded tissue immunohistochemistry staining. For immunofluorescence (IF) analysis, the sections of lung tissues were fixed with $4 \%$ formaldehyde and permeabilized with $0.3 \%$ Triton X-100 in PBS for $10 \mathrm{~min}$ at room temperature. Subsequently, the slides were incubated with $2 \%$ serum-blocking buffer for $20 \mathrm{~min}$ at room temperature and then incubated with specific antibodies. The primary antibodies against $\gamma \mathrm{H} 2 \mathrm{AX}$ (1:200; cat. no. 05-636, EMD Millipore) and 8-OHdG (1:200; cat. no. ab48508, Abcam) were added and incubated at room temperature for $2 \mathrm{~h}$, followed by incubation with the Alexa Fluor 555 conjugated secondary antibody (1:500; cat. no. A32727; Invitrogen; Thermo Fisher Scientific, Inc.) for $1 \mathrm{~h}$. The nuclei were stained with DAPI (cat. no. C1005; Beyotime Institute of Biotechnology) at room temperature for $5 \mathrm{~min}$. Differences in immunostaining were detected by using SP5 Leica confocal microscope with Leica Application Suite Software (version 14.0.0.162, Leica Microsystems $\mathrm{GmbH}$ ).

IF staining. The bronchial epithelial cells $\left(1 \times 10^{5}\right.$ cells) were cultured in the plate on glass slides and cells were subjected to different treatments as follows: i) Control group; ii) HDM group; and iii) HDM combined with RES group. Following treatment, cells were fixed with ice-cold methanol for $10 \mathrm{~min}$ at room temperature and incubated with primary antibody targeting $\gamma \mathrm{H} 2 \mathrm{AX}$ (1:200; cat. no. 05-636; EMD Millipore) 
and 8-OHdG (1:200; cat. no. ab48508; Abcam) at room temperature for $2 \mathrm{~h}$, followed by Alexa Fluor 555 conjugated secondary antibody (1:500; cat. no. A32727; Invitrogen; Thermo Fisher Scientific, Inc.) at room temperature for $1 \mathrm{~h}$. The nuclei were stained with DAPI at room temperature for 5 min. Following staining, the differences were observed by using SP5 Leica confocal microscope with Leica Application Suite Software (version no. 14.0.0.162; Leica Microsystems $\mathrm{GmbH})$.

Western blotting. Western blot analysis was performed as previously described (28). The tissue samples or the cells from various treatment groups were lysed with ice-cold cell lysis buffer plus protease inhibitor, obtained from Thermo Fisher Scientific, Inc. The samples were boiled $10 \mathrm{~min}$ before loading on SDS-PAGE gel. The same amount $(20 \mu \mathrm{g})$ of protein from each group was loaded and separated by $12 \%$ SDS/PAGE electrophoresis and then transferred to a polyvinylidene fluoride membrane. The membranes were blocked by using $5 \%$ skim milk for $60 \mathrm{~min}$ and probed at $4^{\circ} \mathrm{C}$ with specific antibodies overnight, including antibodies against $\gamma \mathrm{H} 2 \mathrm{AX}$ (1:1,000; cat. no. 05-636; EMD Millipore), cleaved caspase-3 (1:1,000; cat. no. 9664; Cell Signaling Technology, Inc.) and GAPDH (1:1,000; cat. no. AF0006; Beyotime Institute of Biotechnology). Immunoreactive protein bands were visualized using horseradish peroxidase-conjugated secondary antibodies (anti-mouse IgG, HRP-linked antibody, 1:1,000; cat. no. 7076; anti-rabbit IgG, HRP-linked Antibody, 1:1,000; cat. no. 7074; all from Cell Signaling Technology., Inc.) and a Clarity Western ECL Substrate (cat. no. 170-5061; Bio-Rad Laboratories, Inc.). The protein bands were analyzed using FluorChem 8900 (ProteinSimple).

Flow cytometry. As previously described, bronchial epithelial cells were cultured in 6-well plates, HDM was used to induce cell apoptosis and HDM combined with RES, NAC or NU7441 were used to determine the effects of RES, NAC and NU7441 on cell apoptosis. After $12 \mathrm{~h}$ of treatment, each group of cells was gently trypsinized and collected $\left(1 \times 10^{5}\right.$ cells were collected in the tube). Each group of cells was suspended in $100 \mu \mathrm{l}$ binding buffer. Subsequently, $5 \mu \mathrm{l}$ Annexin V-FITC and $5 \mu \mathrm{l}$ propidium iodide (cat. no. FXP018; Beijing 4A Biotech Co., Ltd) were added and the cells were incubated at room temperature for $15 \mathrm{~min}$ in the dark. After incubation, $400 \mu \mathrm{l}$ of binding buffer was added to each tube and the percentage of apoptotic cells was analyzed by afluorescence-activated cell sorting instrument (NovoCyte; ACEA Biosciences, Inc.) with NovoExpress ${ }^{\mathrm{TM}}$ software (version no. 1.0.0; ACEA Biosciences, Inc.).

Reactive oxygen species (ROS) measurement. ROS generation in $16 \mathrm{HBE}$ cells was measured using the oxidant-sensitive fluorometric probe DCFH-DA (cat. no. S0033; Beyotime Institute of Biotechnology) according to the manufacturer's protocol. In brief, the cells were cultured in the plate on glass slides and subjected to different treatments as follows: i) Control group; ii), HDM group; iii) RES group; iv) HDM combined with RES group; v) NAC group; and vi) HDM combined with NAC group. After treatment, cells were washed with PBS and then incubated with $10 \mu \mathrm{M}$ DCFH-DA in DMEM for $30 \mathrm{~min}$ at $37^{\circ} \mathrm{C}$. The cells were then washed with PBS and images were captured using a fluorescence microscope (SP5 Leica confocal microscope; Leica Microsystems GmbH).

Frozen lung tissues were incubated with $25 \mu \mathrm{M}$ dihydroethidium (DHE) (cat. no. BB-470515, BestBio) in PBS for $15 \mathrm{~min}$ at $37^{\circ} \mathrm{C}$. The sections were washed with PBS for $3 \mathrm{~min}$ and then imaged using a fluorescence microscope (SP5 Leica confocal microscope; Leica Microsystems GmbH).

ELISA. ELISA assessed the BALF levels of 8-OHdG/8-oxoG in the mice using Mouse 8-OHdG ELISA kit (cat. no. JL12294; Shanghai Jianglai Industrial Limited by Share Ltd.) following the manufacturer's protocol.

Bronchial epithelial cells were cultured in 6-well plates and were subjected to different treatments. The cells were cultured with HDM, with or without the presence of RES and DMSO was used for the control group. After $12 \mathrm{~h}$ of treatment, the cell culture supernatant was collected and the levels of 8-OHdG/8-oxoG were determined using ELISA (cat. no. JL11850, Shanghai Jianglai Industrial Limited by Share Ltd.) according to the manufacturer's protocol.

Statistical analysis. All values are expressed as means \pm standard deviation. Data statistical analysis was performed by SPSS 16.0 (SPSS, Inc.). Student's t-test or one-way analysis of variance (Tukey-Kramer test or Dunnett's T3 post hoc tests) was used to compare data between two groups or multiple groups, respectively. $\mathrm{P}<0.05$ was considered to indicate a statistically significant difference.

\section{Results}

RES attenuates cell apoptosis induced by HDM. In the present study, an asthma mouse model was established in the authors' laboratory and the mice were treated with $\mathrm{HDM} / \mathrm{AI}(\mathrm{OH})_{3}$, followed by HDM (i.n.) with or without RES (i.p.) (Fig. 1A) to detect the pathogenetic mechanism triggered by this exposure. Airway hyperresponsiveness was measured using plethysmographs at $24 \mathrm{~h}$ after the final challenge. The bronchial airway hyper-response was markedly elevated in the mice that are repeatedly exposed to HDM. However, the airway response declined in the mice exposed to HDM in addition to RES compared with the mice exposed to HDM, when the mice were treated with atomized methacholine (Fig. S1). Less extensive inflammatory cell infiltration was observed around the airway in the mice exposed to HDM combined with RES, compared with mice exposed to HDM alone (Fig. 1B). Quantification of airway inflammation index also proved that RES suppressed HDM-induced inflammation (Fig. 1C). Furthermore, treatment with HDM resulted in an increase of the apoptotic cells in airway epithelial cells of lung tissues (Fig. 1D and E). However, mice treated with HDM combined with RES exhibited a significantly decreased percentage of apoptotic cells in the airway epithelial cells of lung tissues. Western blotting revealed that HDM treatment increased the expression level of cleaved caspase-3, whereas treatment with RES resulted in a decrease in the level of cleaved caspase-3 in mice with HDM-induced asthma (Fig. 1F and G). Taken together, these findings indicate that RES attenuates cell apoptosis induced by HDM. 
A

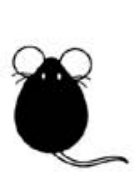

$\mathrm{HDM} / \mathrm{Al}(\mathrm{OH})_{3}$ (i.p.)

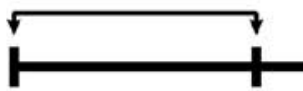

Day 1
HDM (i.n.)

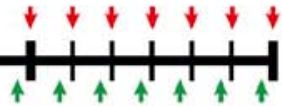

RES (i.g.)

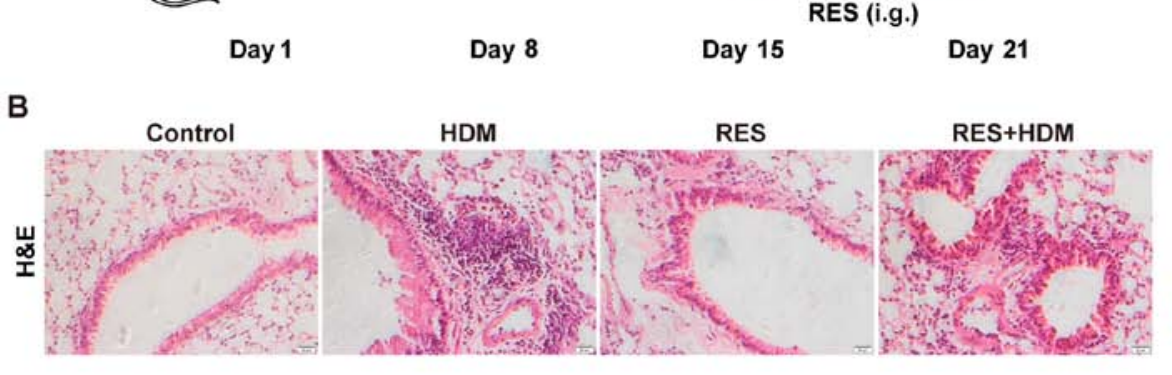

D

\section{TUNEL staining}
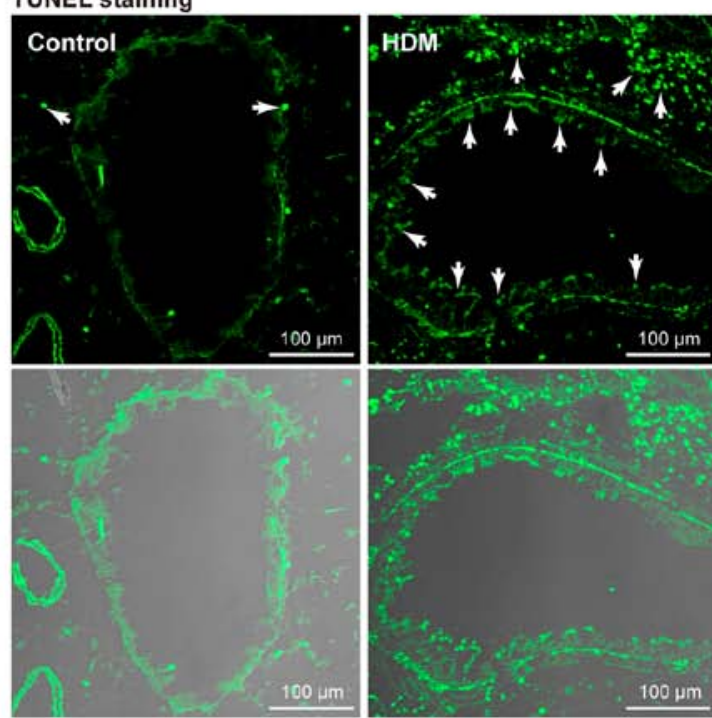

E
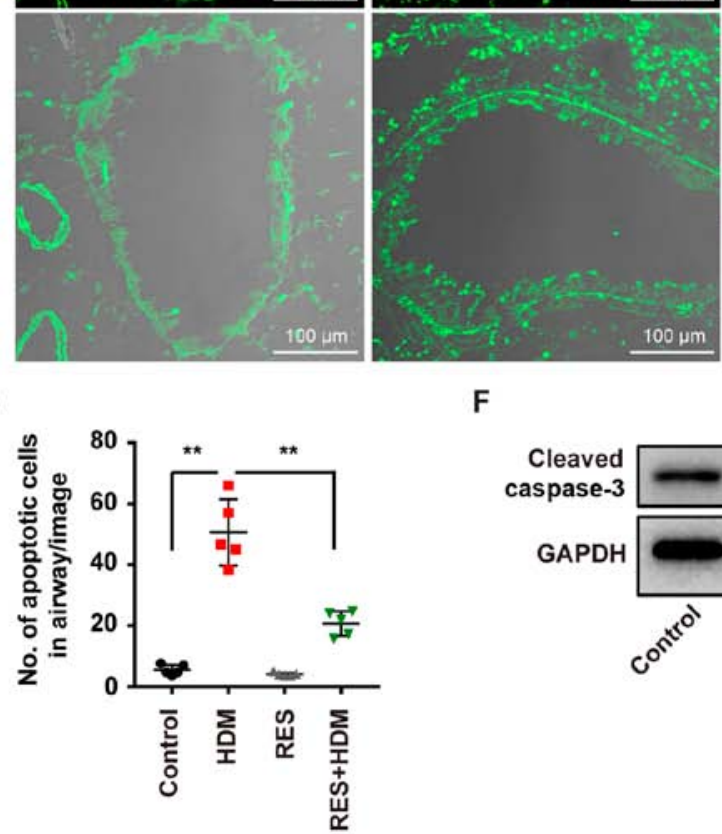

$\mathbf{F}$
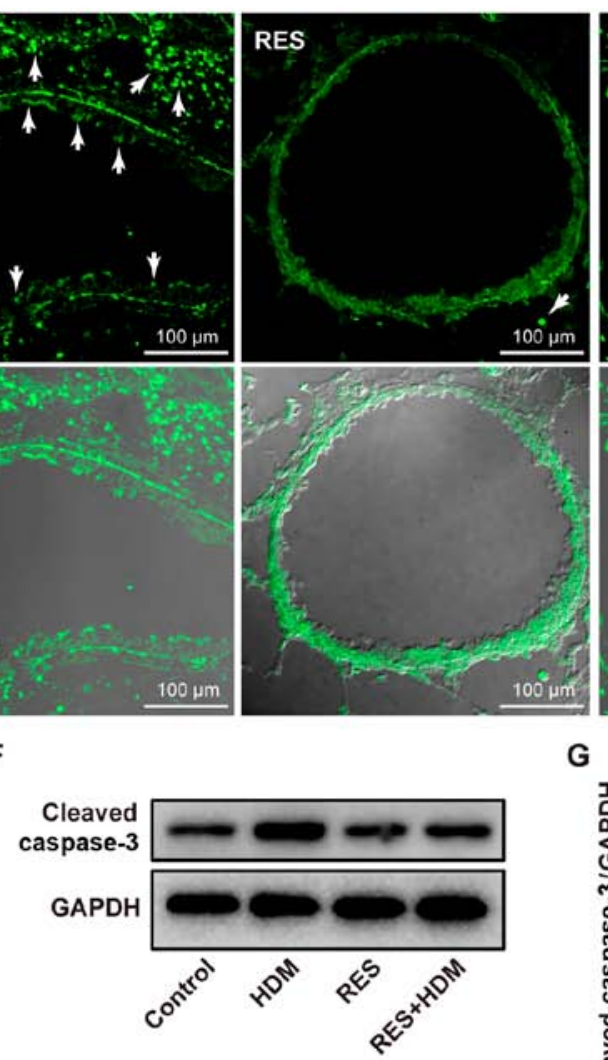
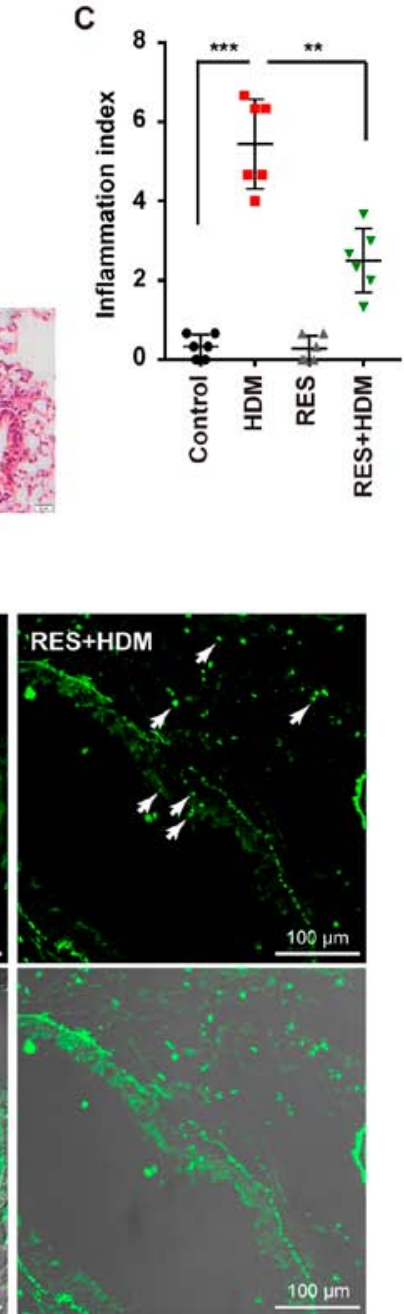

G

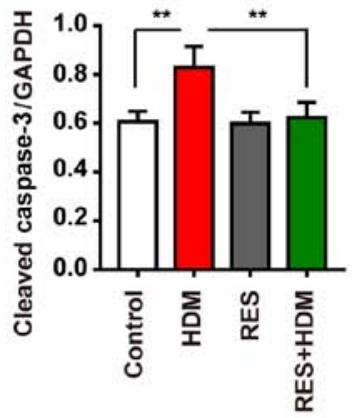

Figure 1. RES attenuates cell apoptosis induced by HDM. (A) Schematic illustration of an experimental protocol for sensitization of cells by HDM, as well as an experimental protocol for mice pre-treated with RES. (B) Representative images of hematoxylin and eosin-stained lung tissue sections (magnification, $\mathrm{x} 200$ ). (C) Quantification of inflammatory cell infiltration in lungs. (D) Representative images of the TUNEL assay. Analysis of apoptosis by using TUNEL assay. (E) Quantification of TUNEL-positive cells. (F) Expression of cleaved caspase-3 was determined by western blot analysis. (G) Relative changes in the density of cleaved caspase-3 $(\mathrm{n}=3)$. Each point represents an individual mouse. Data are presented as mean \pm standard deviation. ${ }^{* *} \mathrm{P}<0.01$ and ${ }^{* * *} \mathrm{P}<0.001$, determined by one-way analysis of variance with Tukey-Kramer test. RES, resveratrol; HDM, house dust mites; i.n., intranasal; TUNEL, terminal deoxynucleotidyl-transferase-mediated dUTP nick end labelling.

RES inhibits oxidative damage and DNA double-strand breaks in the lungs of asthmatic mice. It was revealed that exposure to HDM caused a significant increase in ROS levels (Fig. 2A and B) in a mouse model of asthma and ROS is known to cause DNA damage $(29,30)$. To quantify oxidative damage to nucleic acids, 8-OHdG/8-oxoG levels were detected in BALF and lung tissue. The levels of 8-OHdG were markedly increased in the BALF of mice with HDM-induced asthma and 8-OHdG/8-oxoG could be simultaneously inhibited via treatment with RES (Fig. 2C). IF staining also revealed that RES attenuated 8-OHdG levels in airway epithelial cells of mice with HDM-induced asthma (Fig. 2D and E). To further confirm this finding, another DNA damage-related gene, $\gamma \mathrm{H} 2 \mathrm{AX}$, was analyzed. HDM increased the expression level of $\gamma \mathrm{H} 2 \mathrm{AX}$, which was detected by IF staining (Fig. 2F and $\mathrm{G}$ ) and western blotting (Fig. 2H and I); however, these processes were blocked by treatment with RES, 
A

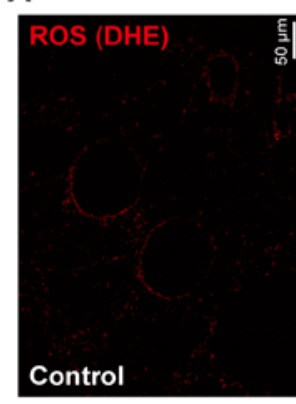

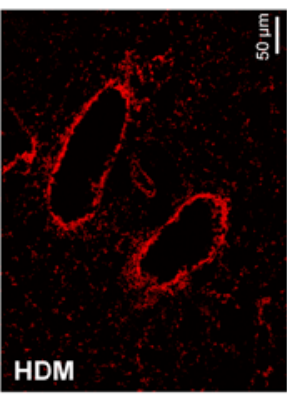

D

$$
\text { C }
$$

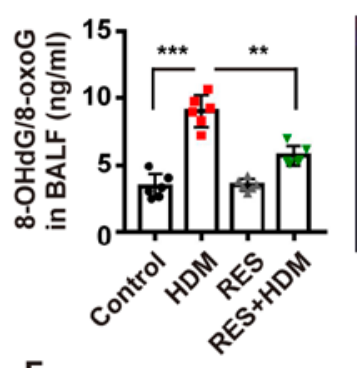

$\mathbf{F}$
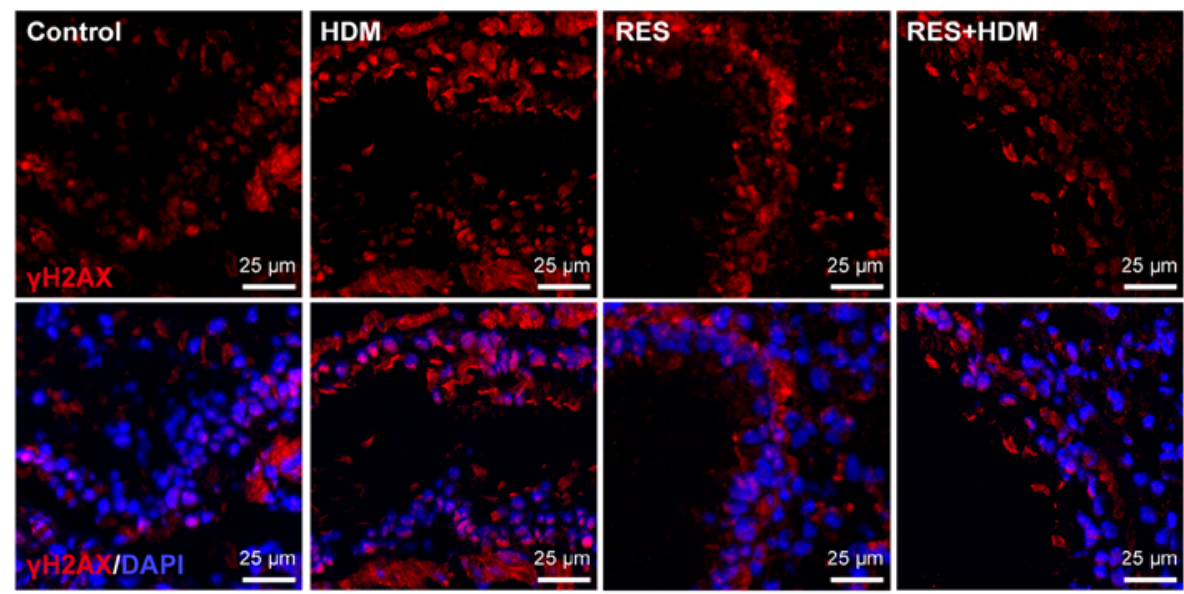

H

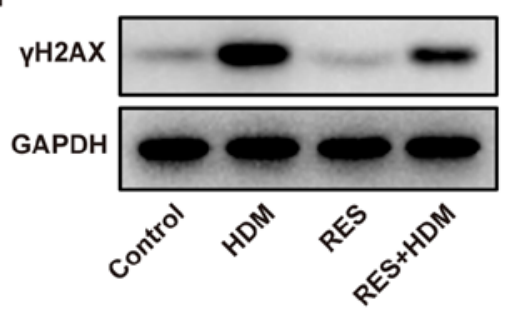

B

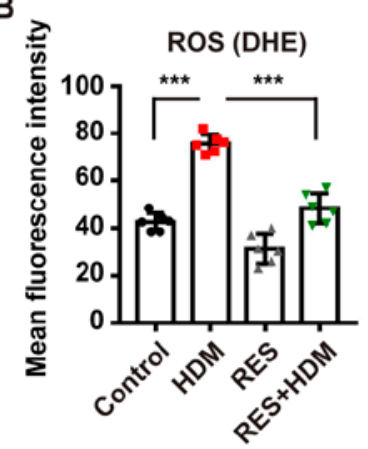

E

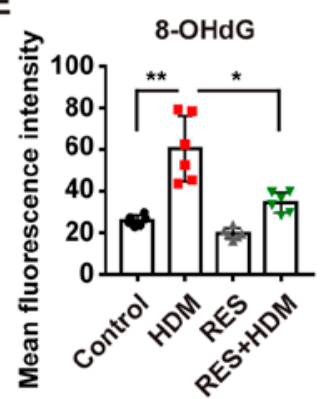

G

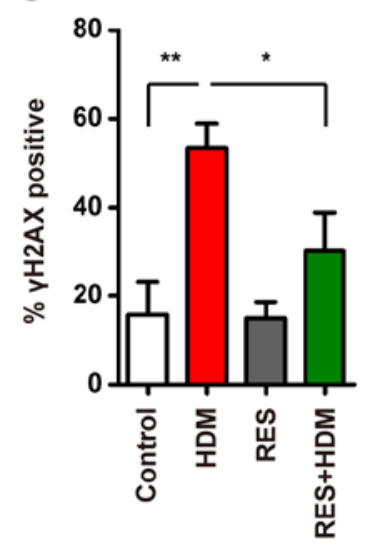

Figure 2. RES inhibits oxidative damage and DNA DSBs in the lungs of asthmatic mice. (A) ROS generation was measured by using DHE assay and (B) quantified. Representative images of DHE as a fluorescent probe and the fold-change of ROS signal intensity are shown. (C) Expression level of 8-OHdG/8-oxoG was measured by ELISA. (D) Lung sections stained with 8-OHdG (red) and DAPI (blue). Representative immunofluorescence images of 8-OHdG in the airway epithelial cells of the mice (magnification, $\mathrm{x} 400$ ). (E) Quantitation of the fluorescence intensity of 8-OHdG. (F) Lung sections stained with $\gamma \mathrm{H} 2 \mathrm{AX}$ (red) and DAPI (blue). Representative sections are shown for the double strand break marker $\gamma \mathrm{H} 2 \mathrm{AX}$ in the nuclei of lung tissues. (G) The percentage of $\gamma \mathrm{H} 2 \mathrm{AX}$-positive cells was determined in the lung tissues $(\mathrm{n}=3)$. (H) The expression level of $\gamma \mathrm{H} 2 \mathrm{AX}$ was determined using western blot analysis. The expression level of GAPDH was used as a loading control. (I) Relative density of $\gamma \mathrm{H} 2 \mathrm{AX}(\mathrm{n}=3)$. Each point represents an individual mouse. Data are presented as the mean \pm standard deviation. One-way analysis of variance with Tukey-Kramer test or Dunnett's T3 test was used. ${ }^{*} \mathrm{P}<0.05,{ }^{* *} \mathrm{P}<0.01$ and ${ }^{* * * *} \mathrm{P}<0.001$. RES, resveratrol; HDM, house dust mites; ROS, reactive oxygen species; DHE, dihydroethidium; BALF, broncho-alveolar lavage fluid.

and the expression level of $\gamma \mathrm{H} 2 \mathrm{AX}$ was decreased. Collectively, these findings suggested that RES can inhibit DNA damage in a mouse model of asthma.
RES attenuates DNA damage in bronchial epithelial cells. The results of the present study demonstrated that HDM can promote cell apoptosis and the increased ROS levels can cause 
A
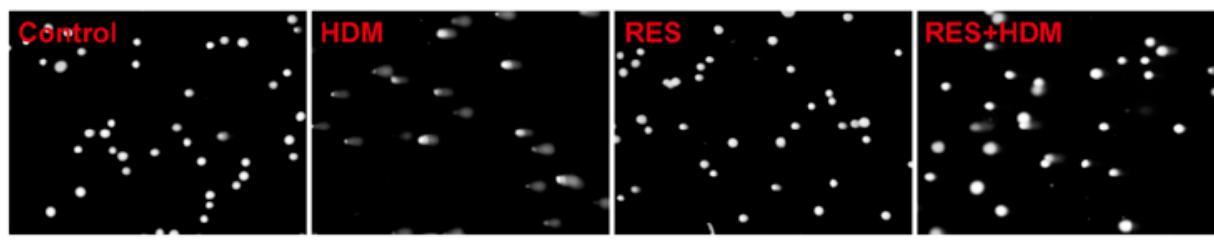

C
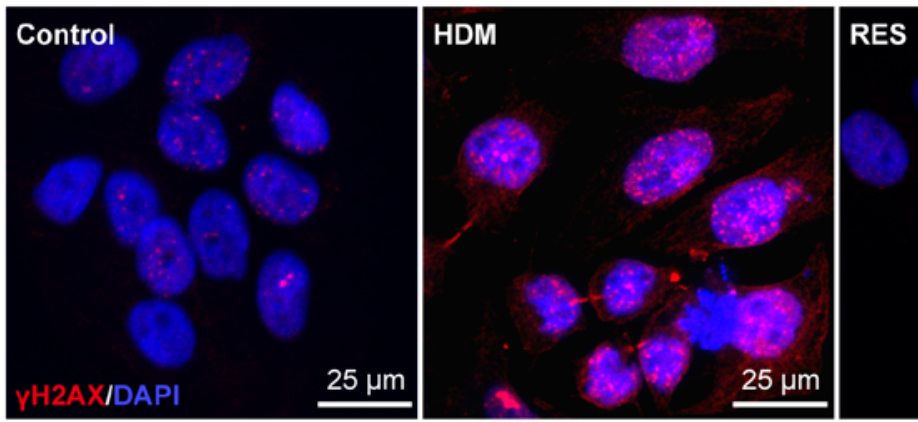

D $\stackrel{8}{\mathrm{~g}}$

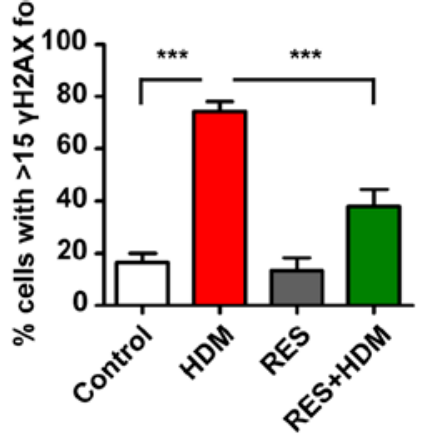

$E$

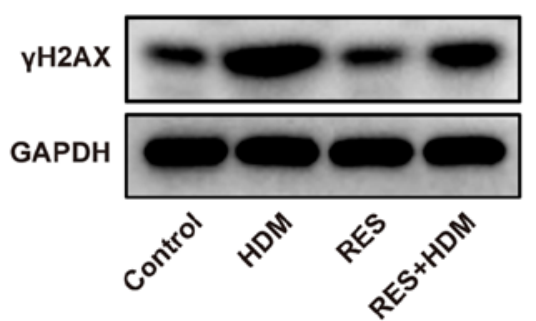

B
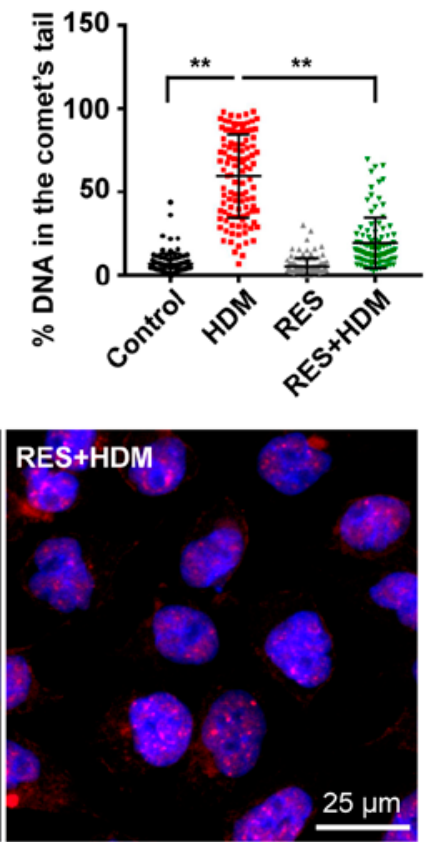

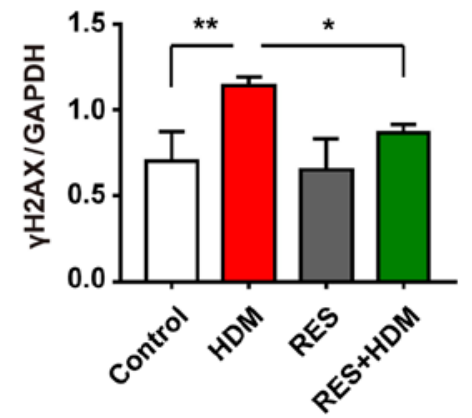

Figure 3. RES attenuates DNA damage in bronchial epithelial cells. 16HBE cells were incubated with RES for $2 \mathrm{~h}$ and then treated with HDM for another $12 \mathrm{~h}$. (A) Representative images of Comet assay (magnification, x400). (B) The percentage of DNA intensity in the Comet tail, reflecting the severity of DNA damage, was quantified. At least 30 individual Comets were analyzed in each treatment group (n=3). (C) Staining with $\gamma \mathrm{H} 2 \mathrm{AX}$ (red) and DAPI (blue). (D) Cells with $>10 \gamma \mathrm{H} 2 \mathrm{AX}$ foci in the bronchial epithelium were considered positive. The percentage of positive cells for $\gamma \mathrm{H} 2 \mathrm{AX}$ foci was determined. (E) The expression level of $\gamma \mathrm{H} 2 \mathrm{AX}$ was determined using western blot analysis. The expression level of GAPDH was used as a loading control. (F) Relative density of $\gamma \mathrm{H} 2 \mathrm{AX}$ on western blot analysis $(n=3)$. Data are presented as the mean \pm standard deviation. One-way analysis of variance with Tukey-Kramer test or Dunnett's T3 test was used. ${ }^{*} \mathrm{P}<0.05,{ }^{* *} \mathrm{P}<0.01$ and ${ }^{* * *} \mathrm{P}<0.001$. RES, resveratrol; HDM, house dust mites.

DNA damage in a mouse asthma model in the airway of lung tissues. However, treatment with RES may attenuate cell apoptosis promoted by HDM and inhibit DNA damage in bronchial epithelial cells therefore these cells were used to further investigate the present hypothesis. It was revealed that DNA damage occurred in the bronchial epithelial cells treated with HDM, as shown in Fig. 3A and B. Increased $\gamma \mathrm{H} 2 \mathrm{AX}$ expression level was detected by immunofluorescence staining (Fig. 3C and D) and western blotting (Fig. 3E and F) in bronchial epithelial cells treated with HDM. However, the level of DNA damage was decreased by combination treatment with HDM and RES (Fig. 3A and B), which was accompanied by a reduction in the expression of $\gamma \mathrm{H} 2 \mathrm{AX}$ (Fig. 3C-F). Taken together, these results indicate that RES attenuates DNA damage induced by HDM in bronchial epithelial cells.

RES decreases ROS generation to inhibit oxidative DNA damage in bronchial epithelial cells. One of characteristics of oxidative stress is increased ROS levels, which may continuously affect the structure of DNA and cause oxidative DNA damage (31). It was previously indicated that treatment of aged rats with RES attenuated oxidative stress in bronchial epithelial cells (32). The present study investigated whether RES could attenuate DNA damage caused by exposure to ROS.

Through detection by DCFH-DA assay, ROS in bronchial epithelial cells were significantly increased after treatment with HDM and the increased ROS levels in bronchial epithelial cells were restored via combination treatment with HDM and RES (Fig. 4A and B). Further testing demonstrated that 8-OHdG/8-oxoG in bronchial epithelial cells, which serves as a marker of oxidative DNA damage, was increased by treatment with HDM and the 8-OHdG/8-oxoG could be simultaneously protected via treatment with RES (Fig. 4C). IF staining also proved that RES attenuated the 8-OHdG level increased by HDM in bronchial epithelial cells (Fig. 4D and E). To further 
A

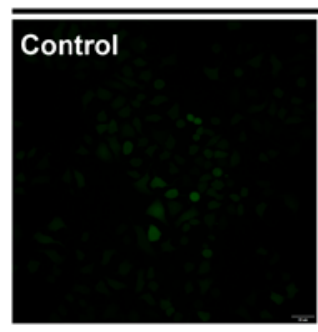

ROS (DCFH-DA)
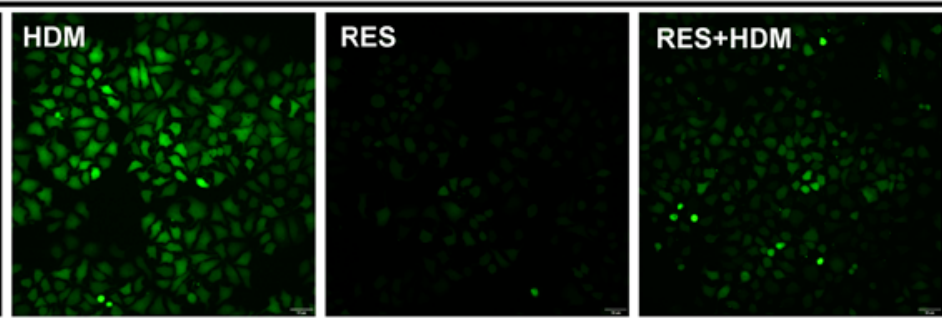

D

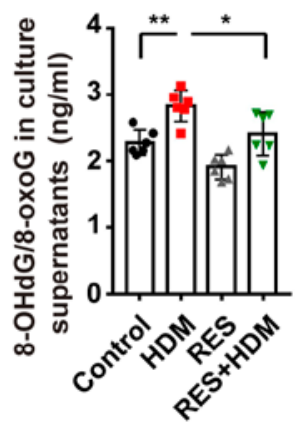

F
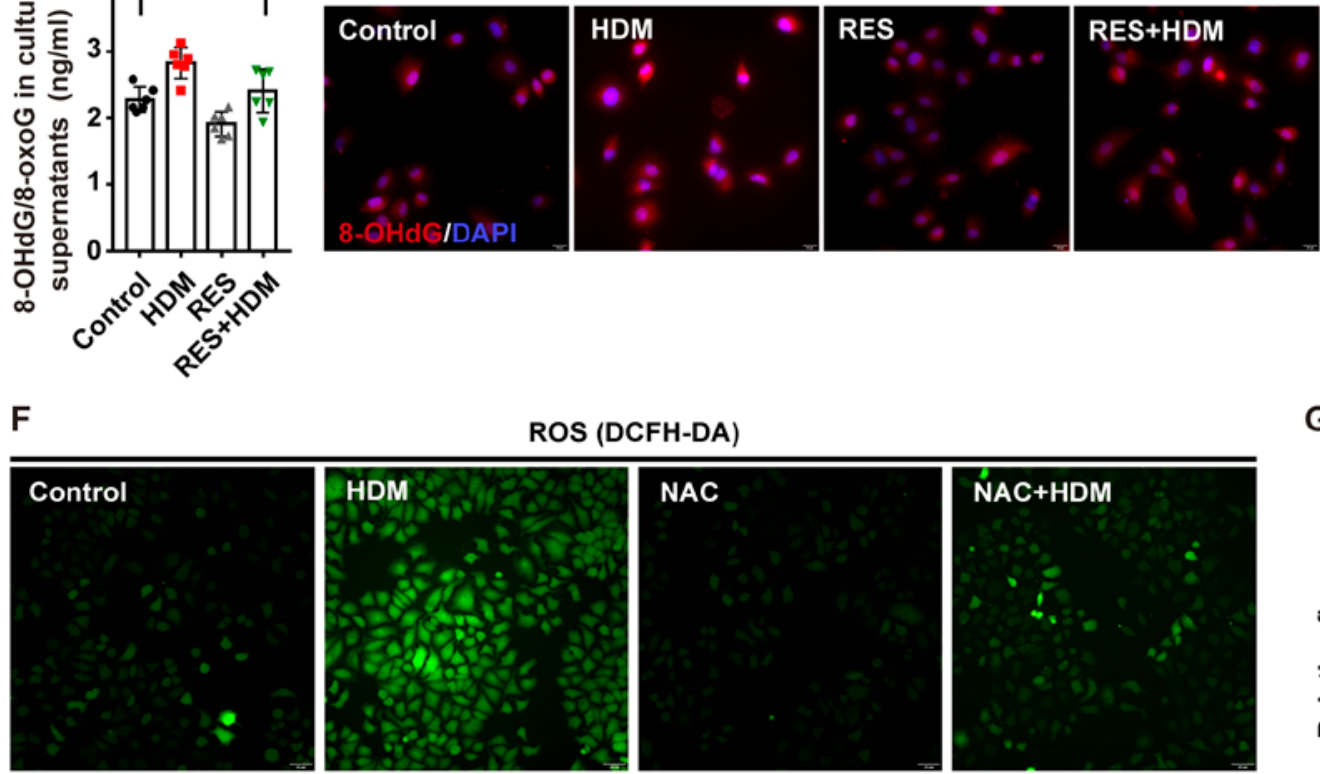

E

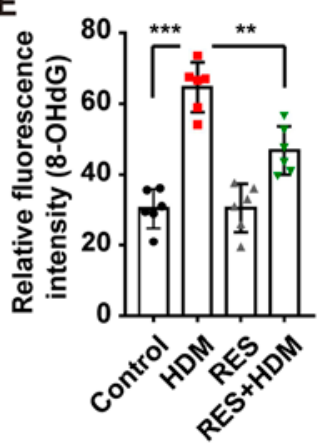

G
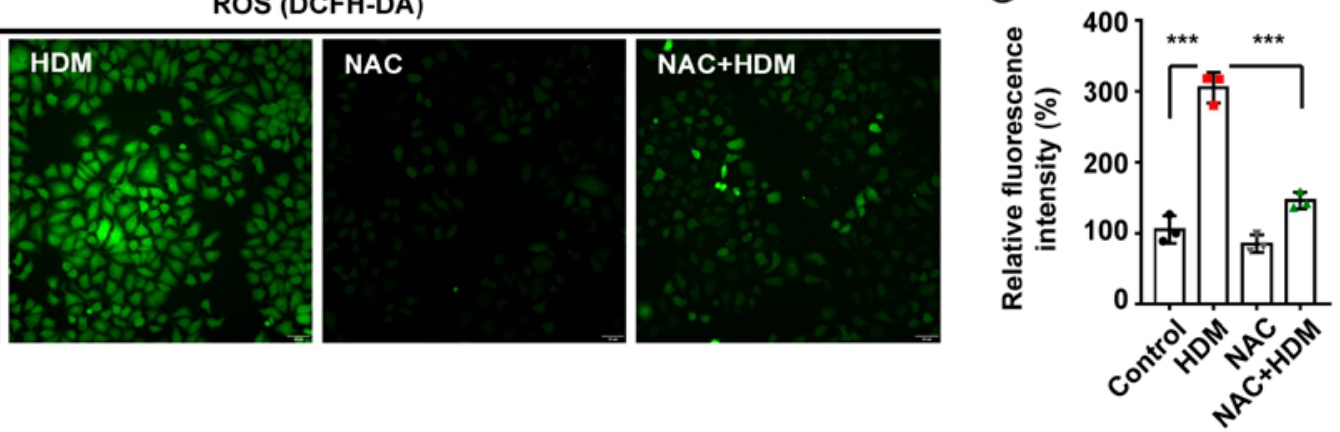

H
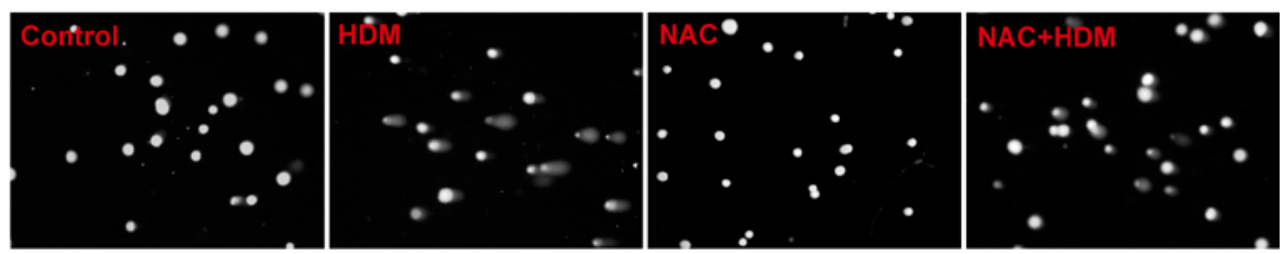

Figure 4. RES decreases ROS to inhibit oxidative DNA damage in bronchial epithelial cells. 16HBE cells were incubated with RES for 2 h and then treated with HDM for another $12 \mathrm{~h}$. (A) Cells were stained with DCFH-DA assay to measure the oxidative stress level and (B) this was quantified. Representative images of DCFH-DA and the fold-change of ROS signal intensity are shown (magnification, x200). (C) The expression level of 8-OHdG/8-oxoG in the culture supernatant was measured by ELISA. (D) Staining with 8-OHdG (red) and DAPI (blue). Representative immunofluorescence images of 8-OHdG (magnification, x400). (E) Quantitation of the fluorescence intensity of 8-OHdG. (F) 16HBE cells were incubated with NAC for $2 \mathrm{~h}$ and then treated with HDM for another $12 \mathrm{~h}$ and $(\mathrm{G})$ the results were quantified. Cells were stained with DCFH-DA to measure the oxidative stress level. Representative images of DCFH-DA and the fold-change of ROS signal intensity are displayed (magnification, x200). (H) Representative images of the Comet assay (magnification, $\mathrm{x} 400$ ). (I) The percentage of DNA intensity in the Comet tail, reflecting the severity of DNA damage, was quantified. At least 30 individual Comets were analyzed in each treatment group $(n=3)$. Data are presented as mean \pm standard deviation. One-way analysis of variance with Tukey-Kramer test or Dunnett's T3 test was used. ${ }^{*} \mathrm{P}<0.05,{ }^{* *} \mathrm{P}<0.01$ and ${ }^{* * *} \mathrm{P}<0.001$. RES, resveratrol; HDM, house dust mites; ROS, reactive oxygen species; NAC, N-acetyl-L-cysteine.

explore the damaging effects of excessive ROS generation on DNA, NAC was used to inhibit the oxidative stress induced by HDM (Fig. 4F). As expected, an elevation in ROS levels was accompanied by increased DNA damage (Fig. 4F-I) following treatment with HDM, while inhibition of ROS generation by NAC was associated with a decrease in DNA damage (Fig. 4F-I). These results suggested that RES inhibits oxidative DNA damage by reducing ROS levels. 


\section{A}
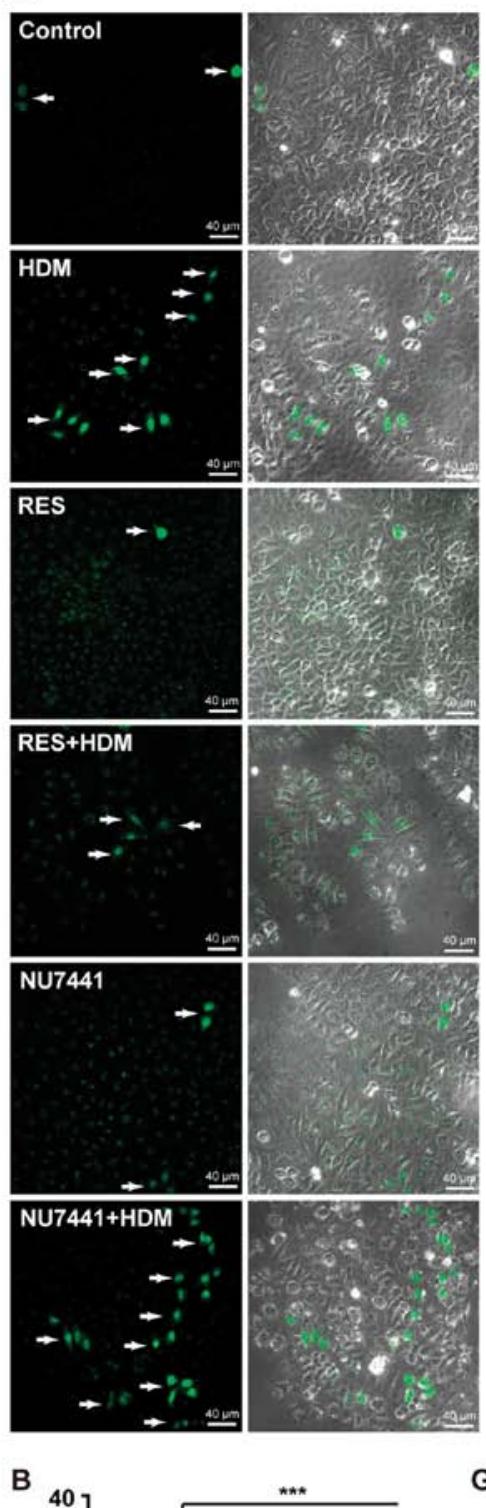

G
C

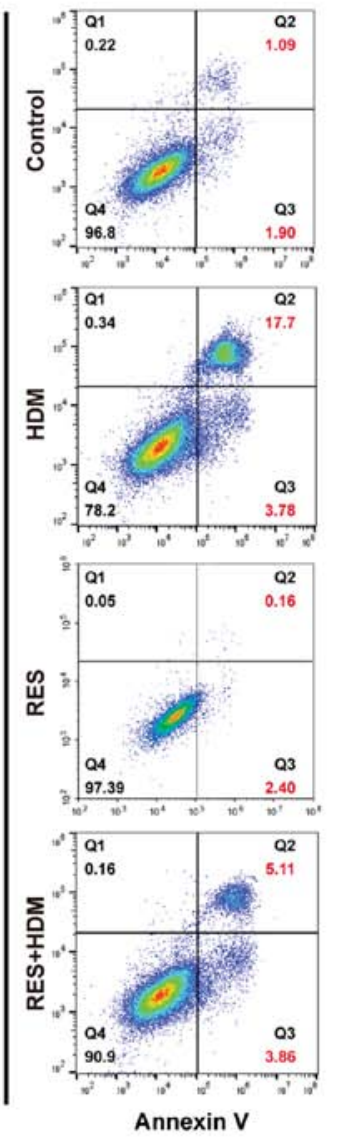

D

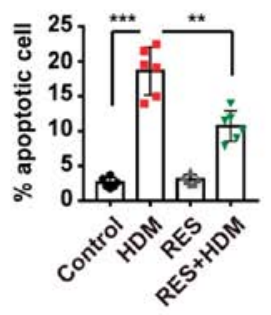

E

PI
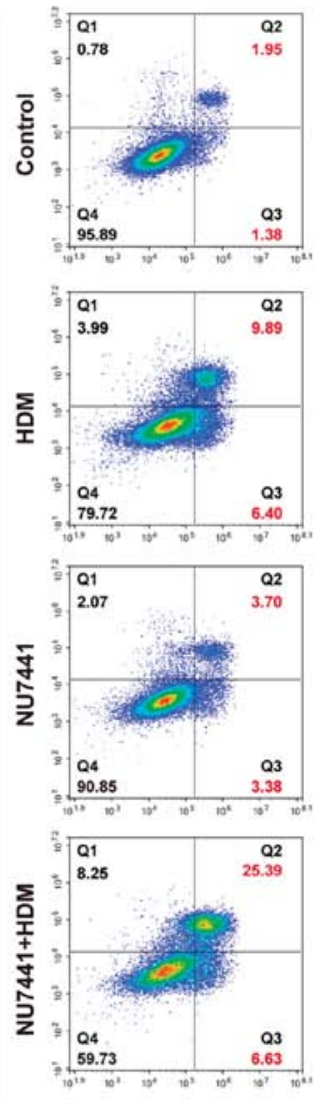

Annexin V

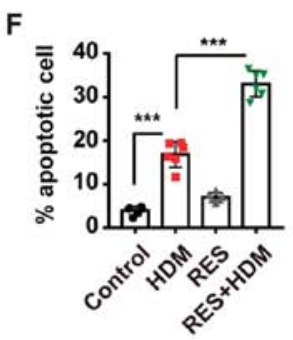

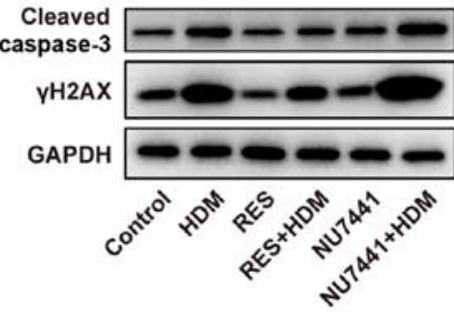

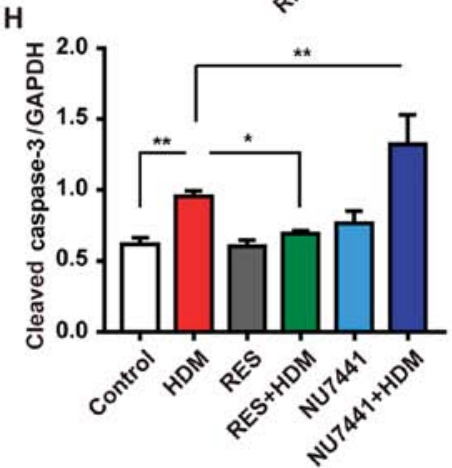

Figure 5. RES protects bronchial epithelial cells from apoptosis induced by HDM treatment. 16HBE cells were incubated with RES or NU7441 for 2 h and then treated with HDM for another $12 \mathrm{~h}$. (A) Representative images of the TUNEL assay which was used to measure apoptosis. (B) Percentage of positive cells in each sample. (C) 16HBE cells were incubated with RES for $2 \mathrm{~h}$ and then treated with HDM for another $12 \mathrm{~h}$. Cell apoptosis was detected by flow cytometry with Annexin V-FITC and PI staining and was (D) quantified. (E) 16HBE cells were incubated with NU7441 for 2 h and then treated with HDM for another $12 \mathrm{~h}$. Cell apoptosis was detected by flow cytometry with Annexin V-FITC and PI staining and was (F) quantified. (G) The expression levels of cleaved caspase-3 and $\gamma \mathrm{H} 2 \mathrm{AX}$ were determined using western blot analysis. $(\mathrm{H})$ Relative density of cleaved caspase-3 and $\gamma \mathrm{H} 2 \mathrm{AX}$ ( $\mathrm{n}=3$ ). Data are presented as mean \pm standard deviation. One-way analysis of variance with Tukey-Kramer test or Dunnett's T3 test was used. ${ }^{*} \mathrm{P}<0.05$, ${ }^{* *} \mathrm{P}<0.01$ and ${ }^{* * * *} \mathrm{P}<0.001$. RES, resveratrol; HDM, house dust mites; PI, propidium iodide.

RES protects bronchial epithelial cells from HDM-induced apoptosis. Of note, $8-\mathrm{OHdG} / 8$-oxoG is a marker of DNA damage $(33,34)$ and $\gamma \mathrm{H} 2 \mathrm{AX}$ also plays a key role in chromatin remodeling and DNA repair, which has already been demonstrated in the current mouse model and bronchial epithelial cell model $(30,35)$. In the present study, it was hypothesized 
A
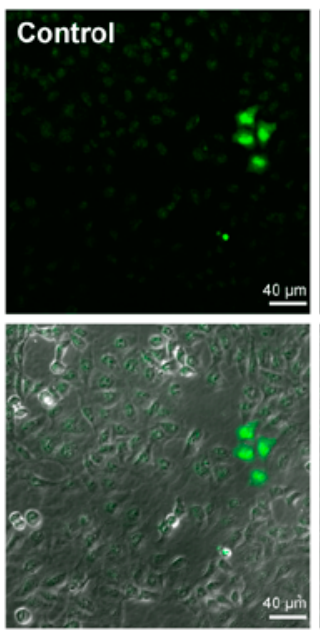

C

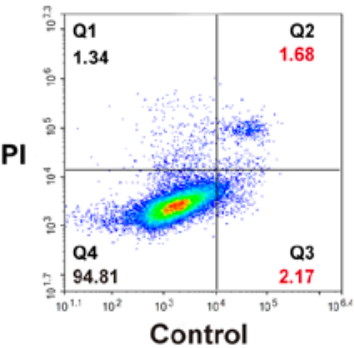

Control
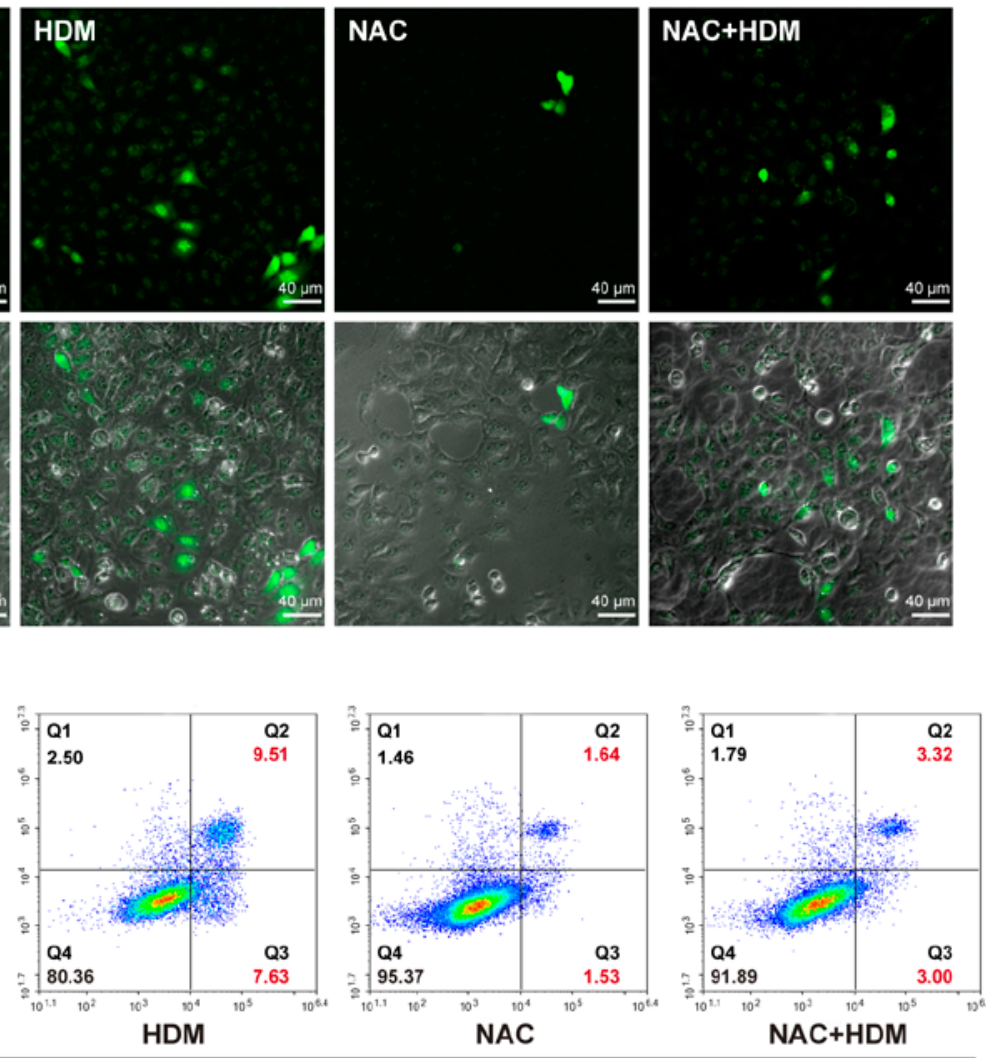

Annexin V

E

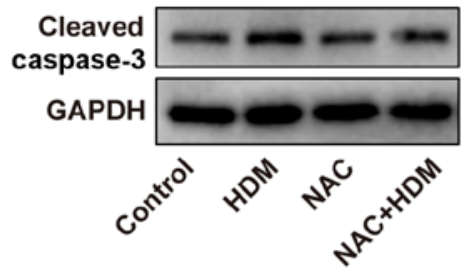

F

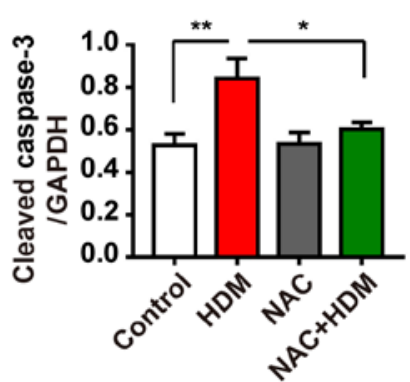

G

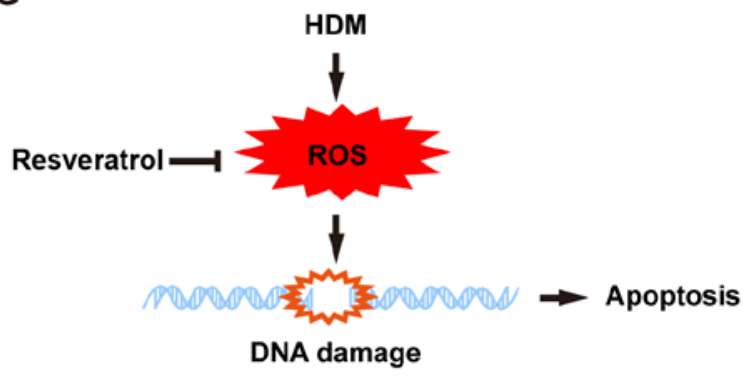

Figure 6. NAC protects bronchial epithelial cells from apoptosis induced by HDM treatment. 16HBE cells were incubated with NAC for $2 \mathrm{~h}$ and then treated with HDM for another $12 \mathrm{~h}$. (A) Apoptosis was measured using TUNEL assay. Representative images of the TUNEL assay. (B) Percentage of positive cells in each sample. (C) Cell apoptosis was detected by flow cytometry with Annexin V-FITC and PI staining and was (D) quantified. (E) The expression level of cleaved caspase-3 was determined using western blot analysis. (F) Relative density of cleaved caspase-3 ( $\mathrm{n}=3$ ). (G) The environmental allergen HDM can induce ROS level increase and cause DNA damage and cell apoptosis in asthma. RES plays a protective antioxidant role and can prevent HDM-induced DNA damage and cell apoptosis of bronchial epithelial cells in allergic asthma. Data are presented as mean \pm standard deviation. One-way analysis of variance with Tukey-Kramer test or Dunnett's T3 test was used. ${ }^{*} \mathrm{P}<0.05,{ }^{* *} \mathrm{P}<0.01$ and ${ }^{* * *} \mathrm{P}<0.001$. RES, resveratrol; NAC, N-acetyl-L-cysteine; HDM, house dust mites; ROS, reactive oxygen species; PI, propidium iodide; TUNEL, Terminal deoxynucleotidyl-transferase-mediated dUTP nick end labelling.

that RES can protect bronchial epithelial cells from apoptosis caused by exposure to HDM. IF staining revealed that the percentage of apoptotic cells was significantly increased following treatment with HDM compared with the PBS control group and this process was inhibited by treatment with RES (Fig. 5A and B). Flow cytometry analysis also confirmed this result (Fig. 5C and D), as the percentage of apoptotic cells among bronchial epithelial cells was increased from 1.09 to $17.7 \%$ following treatment with HDM, whereas it decreased to $5.11 \%$ by the combination of HDM with RES, indicating that RES can attenuate apoptosis of bronchial epithelial cells exposed to HDM. Western blotting also revealed that RES protected cells from apoptosis, resulting in lower expression levels of cleaved caspase-3 with combination treatment with HDM and RES compared with treatment with HDM alone (Fig. 5G and $\mathrm{H}$ ).

To investigate the effects of DNA damage on apoptosis induced by HDM, DNA double-strand breaks repair inhibitor NU7441 was used to inhibit DNA repair. IF staining revealed that HDM-induced apoptosis was further enhanced by NU7441 (Fig. 5A and B). Flow cytometry analysis also demonstrated that NU7441 led to a higher level of HDM-induced apoptosis (Fig. 5E and F). Furthermore, western blotting revealed that NU7441 treatment resulted in an increase in the levels of cleaved caspase- 3 and $\gamma \mathrm{H} 2 \mathrm{AX}$ following combination treatment with HDM and NU7441 compared with treatment with HDM alone 
(Fig. 5G and $\mathrm{H}$ ). In addition, RES inhibited $\gamma \mathrm{H} 2 \mathrm{AX}$ and cleaved caspase-3 in bronchial epithelial cells (Fig. 5G and H). Taken together, these results indicate that RES protects bronchial epithelial cells from apoptosis through preventing DNA damage.

In order to further examine the role of oxidative stress in apoptosis induced by HDM, NAC was used to inhibit the oxidative stress induced by HDM. IF staining revealed that apoptosis was significantly reduced in bronchial epithelial cells treated with HDM and NAC compared with bronchial epithelial cells treated with HDM alone (Fig. 6A and B). Flow cytometry analysis also demonstrated that NAC could attenuate apoptosis of bronchial epithelial cells exposed to HDM (Fig. 6C and D). Furthermore, the western blotting results revealed that NAC reduced cleaved caspase- 3 level in the epithelial cells subjected to HDM treatment (Fig. 6E and F). Collectively, these data indicate that RES protects bronchial epithelial cells from apoptosis through inhibiting oxidative DNA damage (Fig. 6G).

\section{Discussion}

RES is a known antioxidant, which is produced by plants and it can affect multiple human chronic diseases, in addition to interacting with the immune system $(3,4)$. In addition, HDM is a major perennial allergen source and a significant cause of allergic rhinitis and allergic asthma. In the present study, it was hypothesized that HDM can directly induce a high level of ROS generation and cause DNA damage to bronchial epithelial cells, while the antioxidant properties of RES attenuated this process. However, the detailed mechanisms of HDM triggering asthma remain elusive and further investigation may assist physicians to effectively treat patients with asthma through controlling ROS-induced damage to bronchial epithelial cells.

The anti-apoptotic and antioxidant stress-protective effects of RES have been widely investigated. In 2018, Hsu et al (36) revealed that RES could protect A549 human lung epithelial cells against carbon black nanoparticle(CBNP)-induced inflammation and oxidative stress, as CBNPs are known to promote pulmonary toxicity through inflammation and oxidative stress. A previous study used cigarette smoke extract (CSE), which induced apoptosis in a human bronchial epithelial cell model and studied the effects of treatment with or without RES (37). Their results demonstrated that RES exerted a protective effect against CSE-induced apoptosis and a molecular pathway involving Sirtuin 1 (SIRT1) and oxygen-regulated protein 150 , may be associated with the anti-apoptotic function of RES. HBE1 human bronchial epithelial cells were exposed to combined treatment with RES and 4-hydroxynonenal, which acted protectively against cell death caused by oxidative stress, and the Nrf2-EpRE signaling pathway was also involved in this combined therapeutic effect (38). Furthermore, RES also decreased high glucose-induced endothelial cell apoptosis by inhibition of Nox/ROS (39). The results of the present study indicated the anti-apoptotic function of RES in bronchial epithelial cells. Therefore, it may be concluded that RES helps protect cells from apoptosis caused by HDM.

ROS are highly reactive molecules and can damage cell structures such as carbohydrates, nucleic acids, lipids and proteins and alter their functions. The shift in the balance between oxidants and antioxidants in favor of oxidants is termed 'oxidative stress'. Oxidative stress is characterized by the presence of increased ROS levels, either as a result of increased production of ROS or decreased amounts of antioxidants. ROS create a variety of pathological changes in the airways, including increased airway reactivity and increased mucous production, factors that have important implications in asthma (40). The present study demonstrated that exposure to HDM induced high levels of ROS in bronchial epithelial cells in both the mouse model and the cellular model. ROS have been shown to inactivate histone deacetylase-2, which is an essential factor for the inflammatory response (41). RES can improve the expression level of SIRT1 and increase antioxidant production to reduce mitochondrial-associated apoptotic signaling pathways and cell apoptosis and prevent ROS-induced cell damage in myoblasts (42). In the present study, high expression levels of 8-OHdG/8-oxoG were detected, which indicated that the bronchial epithelial cells were damaged. In vitro studies have shown that RES induces the production of antioxidants to reduce the impact of ROS (43-45). A study on RES indicated that treatment of aged rats with RES can activate Nrf2 and attenuate oxidative stress in endothelial cells. It was observed that combined treatment with HDM and RES resulted in lower expression level of ROS and 8-OHdG/8-oxoG. In addition, the Comet assay for DNA damage confirmed that RES can attenuate DNA damage in bronchial epithelial cells caused by HDM. This evidence demonstrated that RES can protect bronchial epithelial cells from oxidative DNA damage due to HDM exposure. DNA repair protects bronchial epithelial cells from HDM-induced DNA damage and apoptosis (2). In the present study, the results also proved that DNA double-strand breaks repair inhibitor NU7441 led to a higher level of HDM-induced apoptosis. Furthermore, the inhibition of ROS production by NAC in HDM-activated bronchial epithelial cells decreased apoptosis.

In conclusion, as one of the most common and important allergens in the environment, HDM can affect the immune system and cause airway allergic diseases, such as asthma. During this process, HDM triggers ROS production and increases DNA damage, which may cause apoptosis of bronchial epithelial cells. RES exerted protective antioxidant effects that prevented HDM-induced DNA damage and apoptosis in bronchial epithelial cells.

\section{Acknowledgements}

Not applicable.

\section{Funding}

The present study was supported by the Health and Family Planning Commission of Sichuan Province (grant nos. 18PJ402 and 16PJ543) and the Doctoral Research Initiation Fund of Affiliated Hospital of Southwest Medical University (grant no. 19045). The funders had no say in the study design, data collection, data analysis, interpretation, or writing of the manuscript.

\section{Availability of data and materials}

The datasets used and/or analyzed during the present study are available from the corresponding author upon reasonable request. 


\section{Authors' contributions}

YZ, LG, VKWW and XingW conceived and designed the research. LG and XingW drafted the manuscript. YZ, LG, BYKL, XL, NM, GX, XiaoyunW and XY performed the experiments. YZ, VKWW, HT, QC and XingW analyzed the data. YZ, LG, VKWW and XingW edited the article. All authors read and approved the final version of the article.

\section{Ethics approval and consent to participate}

All animal experiments (including euthanasia) were in compliance with the regulations and guidelines of the Southwest Medical University Institutional Animal Care Committee and were approved by this committee (approval no. 20160041). In addition, the assays were conducted according to the AAALAC and IACUC guidelines.

\section{Patient consent for publication}

Not applicable.

\section{Competing interests}

The authors declare that they have no competing interests.

\section{References}

1. Sleiman PM, Flory J, Imielinski M, Bradfield JP, Annaiah K, Willis-Owen SA, Wang K, Rafaels NM, Michel S, Bonnelykke K, et al: Variants of DENND1B associated with asthma in children. N Engl J Med 362: 36-44, 2010.

2. Chan TK, Loh XY, Peh HY, Tan WNF, Tan WSD, Li N, Tay IJJ, Wong WSF and Engelward BP: House dust mite-induced asthma causes oxidative damage and DNA double-strand breaks in the lungs. J Allergy Clin Immunol 138: 84-96 e81, 2016.

3. Mukhopadhyay P, Mukherjee S, Ahsan K, Bagchi A, Pacher P and Das DK: Restoration of altered microRNA expression in the ischemic heart with resveratrol. PLoS One 5: e15705, 2010.

4. Vang O, Ahmad N, Baile CA, Baur JA, Brown K, Csiszar A, Das DK, Delmas D, Gottfried C, Lin HY, et al: What is new for an old molecule? Systematic review and recommendations on the use of resveratrol. PLoS One 6: e19881, 2011.

5. Sahiner UM, Birben E, Erzurum S, Sackesen C and Kalayci O: Oxidative stress in asthma. World Allergy Organ J 4: 151-158, 2011.

6. Ba X, Aguilera-Aguirre L, Sur S and Boldogh I: 8-Oxoguanine DNA glycosylase-1-driven DNA base excision repair: Role in asthma pathogenesis. Curr Opin Allergy Clin Immunol 15: 89-97, 2015.

7. Toussaint M, Jackson DJ, Swieboda D, Guedán A, Tsourouktsoglou TD, Ching YM, Radermecker C, Makrinioti H, Aniscenko J, Bartlett NW, et al: Host DNA released by NETosis promotes rhinovirus-induced type-2 allergic asthma exacerbation Nat Med 23: 681-691, 2017.

8. Haswell LE, Hewitt K, Thorne D, Richter A and Gaca MD: Cigarette smoke total particulate matter increases mucous secreting cell numbers in vitro: A potential model of goblet cell hyperplasia. Toxicol In Vitro 24: 981-987, 2010.

9. White SR: Apoptosis and the airway epithelium. J Allergy (Cairo) 2011: 948406, 2011

10. Jang M, Cai L, Udeani GO, Slowing KV, Thomas CF, Beecher CW, Fong HH, Farnsworth NR, Kinghorn AD, Mehta RG, et al: Cancer chemopreventive activity of resveratrol, a natural product derived from grapes. Science 275: 218-220, 1997.

11. Keys A, Menotti A, Karvonen MJ, Aravanis C, Blackburn H, Buzina R, Djordjevic BS, Dontas AS, Fidanza F and Keys MH: The diet and 15-year death rate in the seven countries study. Am J Epidemiol 124: 903-915, 1986.
12. de Lorgeril M, Salen P, Martin JL, Monjaud I, Delaye J and Mamelle N: Mediterranean diet, traditional risk factors, and the rate of cardiovascular complications after myocardial infarction: Final report of the Lyon Diet Heart Study. Circulation 99: 779-785, 1999.

13. Tyagi A, Singh RP, Agarwal C, Siriwardana S, Sclafani RA and Agarwal R: Resveratrol causes Cdc2-tyr15 phosphorylation via ATM/ATR-Chk1/2-Cdc25C pathway as a central mechanism for $\mathrm{S}$ phase arrest in human ovarian carcinoma Ovcar-3 cells. Carcinogenesis 26: 1978-1987, 2005.

14. Vergara D, Simeone P, Toraldo D, Del Boccio P, Vergaro V, Leporatti S, Pieragostino D, Tinelli A, De Domenico S, Alberti S, et al: Resveratrol downregulates Akt/GSK and ERK signalling pathways in OVCAR-3 ovarian cancer cells. Mol Biosyst 8: 1078-1087, 2012.

15. Wang H, Peng Y, Wang J, Gu A, Li Q, Mao D and Guo L: Effect of autophagy on the resveratrol-induced apoptosis of ovarian cancer SKOV3 cells. J Cell Biochem: Nov 18, 2018 (Epub ahead of print).

16. Falchetti R, Fuggetta MP, Lanzilli G, Tricarico M and Ravagnan G: Effects of resveratrol on human immune cell function. Life Sci 70: 81-96, 2001.

17. Ahn J, Cho I, Kim S, Kwon D and Ha T: Dietary resveratrol alters lipid metabolism-related gene expression of mice on an atherogenic diet. J Hepatol 49: 1019-1028, 2008.

18. Hou X, Xu S, Maitland-Toolan KA, Sato K, Jiang B, Ido Y, Lan F, Walsh K, Wierzbicki M, Verbeuren TJ, et al: SIRT1 regulates hepatocyte lipid metabolism through activating AMP-activated protein kinase. J Biol Chem 283: 20015-20026, 2008.

19. Baur JA, Pearson KJ, Price NL, Jamieson HA, Lerin C, Kalra A, Prabhu VV, Allard JS, Lopez-Lluch G, Lewis K, et al: Resveratrol improves health and survival of mice on a high-calorie diet. Nature 444: 337-342, 2006.

20. Lagouge M, Argmann C, Gerhart-Hines Z, Meziane H, Lerin C, Daussin F, Messadeq N, Milne J, Lambert P, Elliott P, et al: Resveratrol improves mitochondrial function and protects against metabolic disease by activating SIRT1 and PGC-1alpha. Cell 127: 1109-1122, 2006.

21. Carter LG, D'Orazio JA and Pearson KJ: Resveratrol and cancer: Focus on in vivo evidence. Endocr Relat Cancer 21: R209-R225, 2014.

22. Chen ZH, Hurh YJ, Na HK, Kim JH, Chun YJ, Kim DH, Kang KS, Cho MH and Surh YJ: Resveratrol inhibits TCDD-induced expression of CYP1A1 and CYP1B1 and catechol estrogen-mediated oxidative DNA damage in cultured human mammary epithelial cells. Carcinogenesis 25: 2005-2013, 2004.

23. Lee M, Kim S, Kwon OK, Oh SR, Lee HK and Ahn K: Anti-inflammatory and anti-asthmatic effects of resveratrol, a polyphenolic stilbene, in a mouse model of allergic asthma. Int Immunopharmacol 9: 418-424, 2009.

24. Royce SG, Dang W, Yuan G, Tran J, El Osta A, Karagiannis TC and Tang ML: Resveratrol has protective effects against airway remodeling and airway hyperreactivity in a murine model of allergic airways disease. Pathobiol Aging Age Relat Dis 1: 2011.

25. Aich J, Mabalirajan U, Ahmad T, Khanna K, Rehman R, Agrawal A and Ghosh B: Resveratrol attenuates experimental allergic asthma in mice by restoring inositol polyphosphate 4 phosphatase (INPP4A). Int Immunopharmacol 14: 438-443, 2012.

26. André DM, Calixto MC, Sollon C, Alexandre EC, Leiria LO, Tobar N, Anhê GF and Antunes E: Therapy with resveratrol attenuates obesity-associated allergic airway inflammation in mice. Int Immunopharmacol 38: 298-305, 2016.

27. Lee HY, Kim IK, Yoon HK, Kwon SS, Rhee CK and Lee SY: Inhibitory effects of resveratrol on airway remodeling by transforming growth factor- $\beta /$ smad signaling pathway in chronic asthma model. Allergy Asthma Immunol Res 9: 25-34, 2017.

28. Zhang Y, Tang H, Yuan X, Ran Q, Wang X, Song Q, Zhang L, Qiu Y and Wang X: TGF- $\beta 3$ promotes MUC5AC hyper-expression by modulating autophagy pathway in airway epithelium. Ebiomedicine 33: 242-252, 2018.

29. Pan MR, Li K, Lin SY and Hung WC: Connecting the dots: From DNA damage and repair to aging. Int J Mol Sci 17: E685, 2016.

30. Leysen H, van Gastel J, Hendrickx JO, Santos-Otte P, Martin B and Maudsley S: G protein-coupled receptor systems as crucial regulators of DNA damage response processes. Int J Mol Sci 19: E2919, 2018.

31. Knaapen AM, Schins RP, Polat D, Becker A and Borm PJ: Mechanisms of neutrophil-induced DNA damage in respiratory tract epithelial cells. Mol Cell Biochem 234-235: 143-151, 2002. 
32. Csiszar A, Csiszar A, Pinto JT, Gautam T, Kleusch C, Hoffmann B, Tucsek Z, Toth P, Sonntag WE and Ungvari Z: Resveratrol encapsulated in novel fusogenic liposomes activates Nrf 2 and attenuates oxidative stress in cerebromicrovascular endothelial cells from aged rats. J Gerontol A Biol Sci Med Sci 70: 303-313, 2015.

33. Whitaker AM, Schaich MA, Smith MR, Flynn TS and Freudenthal BD: Base excision repair of oxidative DNA damage: From mechanism to disease. Front Biosci (Landmrk Ed) 22 1493-1522, 2017.

34. Zeng H, Nanayakkara GK, Shao Y, Fu H, Sun Y, Cueto R, Yang WY, Yang Q, Sheng H, Wu N, et al: DNA checkpoint and repair factors are nuclear sensors for intracellular organelle stresses - inflammations and cancers can have high genomic risks. Front Physiol 9: 516, 2018.

35. Rajendran P, Ho E, Williams DE and Dashwood RH: Dietary phytochemicals, HDAC inhibition, and DNA damage/repair defects in cancer cells. Clin Epigenetics 3: 4, 2011.

36. Hsu HT, Tseng YT, Wong WJ, Liu CM and Lo YC: Resveratrol prevents nanoparticles-induced inflammation and oxidative stress via downregulation of PKC- $\alpha$ and NADPH oxidase in lung epithelial A549 cells. BMC Complement Altern Med 18: 211 , 2018.

37. Zhang L, Guo X, Xie W, Li Y, Ma M, Yuan T and Luo B Resveratrol exerts an anti-apoptotic effect on human bronchial epithelial cells undergoing cigarette smoke exposure. Mol Med Rep 11: 1752-1758, 2015.

38. Zhang H, Shih A, Rinna A and Forman HJ: Resveratrol and 4-hydroxynonenal act in concert to increase glutamate cysteine ligase expression and glutathione in human bronchial epithelial cells. Arch Biochem Biophys 481: 110-115, 2009.

39. Chen F, Qian LH, Deng B, Liu ZM, Zhao Y and Le YY: Resveratrol protects vascular endothelial cells from high glucose-induced apoptosis through inhibition of NADPH oxidase activation-driven oxidative stress. Cns Neurosci Ther 19 675-681, 2013.
40. Lugogo NL, Bappanad D and Kraft M: Obesity, metabolic dysregulation and oxidative stress in asthma. Biochim Biophys Acta 1810: 1120-1126, 2011.

41. Ito K, Hanazawa T, Tomita K, Barnes PJ and Adcock IM Oxidative stress reduces histone deacetylase 2 activity and enhances IL-8 gene expression: Role of tyrosine nitration. Biochem Biophys Res Commun 315: 240-245, 2004.

42. Haramizu S, Asano S, Butler DC, Stanton DA, Hajira A, Mohamed JS and Always SE: Dietary resveratrol confers apoptotic resistance to oxidative stress in myoblasts. J Nutr Biochem 50: 103-115, 2017.

43. Montesano A, Luzi L, Senesi P, Mazzocchi N and Terruzzi I: Resveratrol promotes myogenesis and hypertrophy in murine myoblasts. J Transl Med 11: 310, 2013.

44. Cosín-Tomàs M, Senserrich J, Arumí-Planas M, Alquézar C, Pallàs M, Martín-Requero Á, Suñol C, Kaliman P and Sanfeliu C: Role of resveratrol and selenium on oxidative stress and expression of antioxidant and anti-aging genes in immortalized lymphocytes from Alzheimer's disease patients. Nutrients 11: E1764, 2019.

45. Zhuang Y, Wu H, Wang X, He J, He S and Yin Y: Resveratrol attenuates oxidative stress-induced intestinal barrier injury through PI3K/Akt-mediated Nrf2 signaling pathway. Oxid Med Cell Longev 2019: 7591840, 2019.

This work is licensed under a Creative Commons Attribution-NonCommercial-NoDerivatives 4.0 International (CC BY-NC-ND 4.0) License. 